\title{
PENGARUH KUALITAS MAKANAN, KUALITAS LAYANAN, DAN LINGKUNGAN FISIK RESTORAN TERHADAP KEPUASAN SERTA NIAT BERPERILAKU
}

\author{
Gita Ekowati Anjarsari ${ }^{1}$ \\ Ni Wayan Sri Suprapti ${ }^{2}$ \\ I Putu Gde Sukaatmadja ${ }^{3}$ \\ ${ }^{1,2,3}$ Program Pasca Sarjana Universitas Udayana, Bali, Indonesia \\ e-mail: gitagitaa@rocketmail.com
}

\begin{abstract}
ABSTRAK
Studi ini bertujuan untuk menjelaskan pengaruh kualitas makanan, kualitas layanan dan lingkungan fisik terhadap kepuasaan serta niat berperilaku. Sampel yang digunakan sebanyak 150 responden yang diambil menggunakan teknik purposive sampling yaitu tingkat pendidikan minimal SMA atau sederajat, berdomisili di Kabupaten Badung, Kuta dan pernah bersantap di restoran Nanny's Pavillon minimal dua kali dalam enam bulan terakhir. Data dianalisis menggunakan Structural Equation Model (SEM). Hasil penelitian ini menunjukkan bahwa kualitas makanan, kualitas layanan, dan lingkungan fisik memiliki pengaruh yang positif dan signifikan terhadap kepuasaan pelanggan. Kepuasaan juga berpengaruh positif dan signifikan terhadap niat berperilaku. Implikasi penelitian ini menunjukkan bahwa pelanggan Nanny's Pavillon lebih mengutamakan kualitas makanan seperti, tampilan yang menarik, menu yang beragam, rasa yang nikmat, serta suhu hidangan sesuai dengan yang seharusnya, lingkungan fisik yang menarik juga memberilan kepuasan pada pelanggan. Disarankan bagi manajemen Nanny's Pavillon untuk lebih memperhatikan pelayanan agar kepuasan pelanggan dapat lebih ditingkatkan sehingga akan mempengaruhi niat berperilaku pelanggan lebih baik lagi dimasa mendatang.

1
\end{abstract}

Kata kunci: Kualitas Makanan, kualitas layanan, Lingkungan fisik, Kepuasaan, Niat berperilaku

\begin{abstract}
The purpose of this study is to explain the effects of food quality, service quality, and physical environment on customer satisfaction and behavioral intention. The sample used are 150 respondents using purposive sampling who have minimal education of senior high school or equal and have been in Nanny's Pavillon at least twice in the last six months. Data Analyzed using Structural Equation Model (SEM). The results of this study indicate the construct of food quality, service quality, and physical environment has positive and significant effects on customer satisfaction and behavioral intention. The implications on this research show that the customer of Nanny's Pavillon chooses the food quality such as the catchy food display, variety of the menu, delicious food, also the temperature of the dish as appropriate. The advices for Nanny's Pavillon managements are to pay more attention to the service,Therefore, the satisfaction of Nanny's Pavillon customer can be increase so then will effects on behavioral intention in the future.
\end{abstract}

Keywords: Food Quality, Service Quality, Physical Environment, Satisfaction, Behavioral Intention 


\section{PENDAHULUAN}

Industri kepariwisataan di Indonesia sekarang ini berkembang cukup pesat. Meningkatnya wisatawan domestik maupun asing untuk melakukan perjalanan wisata menjadi peluang sekaligus tantangan bagi pengembangan pariwisata, khususnya dari sisi penyedia sarana pariwisata, seperti rumah makan atau restoran. Bisnis restoran di beberapa kota besar di Indonesia, seperti di Bali, pada umumnya mengalami peningkatan. Data yang di publikasikan oleh Badan Pusat Statistik Kabupaten Badung pada tahun 2016 menujukkan pada tahun 2011 terdapat 384 unit restoran, pada tahun 2012 terdapat 469 unit restoran, pada tahun 2013 terdapat 567 unit restoran, pada tahun 2014 terdapat 668 unit restoran dan pada tahun 2015 terdapat 833 unit restoran. (www.bali.bps.go.id, diakses tanggal 16 Nopember 2016). Data tersebut menunjukan bahwa adanya peningkatan bisnis restoran dari tahun 2011 hingga tahun 2015.

Beberapa wilayah seperti Kuta, Seminyak, Jimbaran dan Nusa dua merupakan jantung pariwisata dari Kabupaten Badung sehingga tidak mengherankan jika banyak restoran yang dapat dijumpai pada wilayah tersebut, dengan berbagai tipe restoran serta jenis hidangan yang ditawarkan. Peningkatan jumlah restoran juga disebabkan oleh gaya hidup masyarakat menengah ke atas yang kini lebih senang untuk bersantap di restoran sebagai sarana hiburan serta sosialisai karena dipandang praktis. Fenomena saat ini, banyak pelanggan yang mencari sebuah restoran di mana bukan hanya menawarkan varian menu unik dengan harga yang wajar tapi juga menawarkan 
pengalaman yang baik dari lingkunagn fisik restoran dan pelayanan yang hangat (Canny, 2014). Konsep sebuah restoran pada saat ini menjadi harus lebih bervariasi, sehingga menjadi kunci keunggulan dari sebuah restoran. (Leoma, 2014).

Casual dining restaurant merupakan restoran keluarga dengan sistem pelayanan yang santai dan hangat, Sesuai namanya umumnya ramai dikunjungi pada saat jam makan siang dan malam. Restoran gaya kasual bisa hadir dalam berbagai tema menyesuaikan dengan sajian menu yang ditawarkan. Restoran gaya kasual menawarkan layanan meja, piring bergaya casual. Restoran sejenis ini umumnya banyak ditemukan di daerah pariwisata atau perkotaan. Nanny's Pavillon adalah salah satu Casual dining restaurant ternama di Indonesia, Nanny's Pavillon didirikan sejak 23 maret 2009 dan pertama kali membuka restorannya di Bandung dan memiliki menu yang unik yang berasal dari tradisi keluarga di Amerika. Restoran Nanny's Pavillon memiliki 18 outlet di seluruh Indonesia. Nanny's Pavillon cabang Beachwalk Mall, Bali yang bertemakan "Bareel storage" dengan konsep restoran yang homey dengan tetap mengusung tema french american country style dengan dominasi warna hijau dan putih.

Setiap restoran harus menemukan cara untuk mempertahankan dan menarik pelanggan baru, di mana pada saat yang sama restoran harus tetap kompetitif dan menguntungkan. Ryu dan Han (2010) menyatakan bahwa kepuasan pelanggan menjadi salah satu prioritas utama pemasaran karena umumnya diasumsikan sebagai determinan yang signifikan dari penjualan kembali word-of-mouth yang positif serta loyalitas pelanggan. Kepuasan 
Gita Ekowati Anjarsari, Ni Wayan Sri Suprapti, dan I Putu Gde Sukaatmadja. Pengaruh Kualitas...

pelanggan dianggap sebagai penentu sikap pasca-pembelian dan mencerminkan sebagai hasil yang positif atau negatif (Canny,2014). Beberapa studi terdahulu di berbagai jenis restoran mengungkapkan bahwa pengalaman makan memiliki pengaruh yang positif terhadap kepuasaan pelanggan serta sebagai prediktor dari niat berperilaku (Ryu dan Han,2010; Ryu et al., 2011; Namkung dan Jang, 2010). Komponen pengalaman makan yang mempengaruhi kepuasan pelanggan restoran antara lain kualitas makanan (Namkung dan Jang, 2010), kualitas layanan (Andaleeb dan Conway,2006; Qin dan Prybutok, 2008) dan kualiats lingkungan Fisik (Hersanti dan Ratnawati, 2012; serta Canny, 2014). Kualitas makanan merupakan sesuatu hal penting yang dipertimbangkan ketika mengkonsumsi suatu makanan, hal tersebut mencakup faktor-faktor kualitas seperti suhu makanan, kesegaran makanan, dan persiapan makanan. Sebagai produk inti dari sebuah restoran, makanan memainkan peran sangat penting. Kualitas makanan yang disajikan umumnya merupakan sebuah faktor utama yang dapat mempengaruhi kepuasan pelanggan dan perilaku niat pelanggan (Jang, 2011). Kualitas layanan merupakan bagian yang tidak terpisahkan dengan kepuasan pelanggan. Kualitas layanan berasal dari interaksi antara pelayan dan pelanggan restoran, kemampuan untuk melayani layanan yang dijanjikan, kepedulian karyawan dan perhatian karyawan kepada setiap pelanggan, wawasan pelayan, kemampuan dan percaya diri pelayan dalam menghadapi pelanggan, serta penampilan professional dari karyawan yang akan menghasilkan kepuasan pelanggan (Ryu dan Han, 2010). 
Di industri restoran, pelanggan tidak hanya mengevaluasi kualitas makanan tetapi juga mengevaluasi pelayanan selama mereka bersantap, kualitas layanan dipandang sebagai penentu inti dari kepuasan pelanggan dan perilaku niat pelanggan (Liu dan jang, 2009). Kepuasaan pelanggan merupakan hal yang sangat penting untuk bisnis apapun. Kepuasan pelanggan akan menentukan niat berperilaku pelanggan setelah pelanggan memiliki pengalaman bersantap di sebuah restoran (Canny, 2014). Niat berperilaku merupakan hasil dari proses kepuasan pelanggan, dari sini pelaku usaha akan mengetahui bagaimana kecenderungan niat berperilaku dari kepuasaan pelanggannya (Leoma, 2014).

Banyak penelitian yang membahas mengenai faktor-faktor yang mempengaruhi niat berperilaku seperti lingkungan fisik, kualitas makanan, kualitas layanan, dan kepuasaan pelanggan. (Ha \& Jang, 2010; Jang \& Namkung, 2009; Liu \& Jang, 2009) pernah meneliti bahwa niat berperilaku berkaitan dengan customer satisfaction. Kisang Ryu, 2012 pernah meneliti bahwa atmospheric, service quality dan food quality berpengaruh pada perceived value. Ryu Jang, 2012; Lee, 2012 meneliti bahwa perceived value berperngaruh pada customer satisfaction. Canny (2014) juga meneliti bahwa customer satisfaction berpengaruh pada niat berperilaku. Namun berbeda dengan beberapa penelitian sebelumnya yang di lakukan oleh zainuddin (2015) bahwa lingkungan fisik, kualitas makanan, kualitas layanan, tidak berpengaruh secara signifikan terhadap kepuasaan pelanggan. Berdasarkan paparan tersebut 
Gita Ekowati Anjarsari, Ni Wayan Sri Suprapti, dan I Putu Gde Sukaatmadja. Pengaruh Kualitas...

penelitian ini bertujuan untuk menjelaskan pengaruh kualitas makanan, kualitas layanan, dan lingkungan fisik restoran terhadap kepuasan serta niat berperilaku.

Pemaparan sekilas tentang hasil- hasil studi di atas menunjukan pengaruh pengalaman makan terhadap kepuasan dan niat berperilaku pengunjung restoran. Kualitas makanan, layanan, dan lingkungan restoran merupakan komponen penting restoran yang perlu dioptimalkan untuk meningkatkan daya saing restoran. Hal tersebut penting bagi casual dining restaurant yang juga beroperasi di Bali.

Casual dining restaurant merupakan restoran keluarga dengan sistem pelayanan yang santai dan hangat, Sesuai namanya umumnya ramai dikunjungi pada saat jam makan siang dan malam. Restoran gaya kasual bisa hadir dalam berbagai tema menyesuaikan dengan sajian menu yang ditawarkan. Restoran gaya kasual menawarkan layanan meja, piring bergaya casual. Restoran sejenis ini umumnya banyak ditemukan di daerah pariwisata atau perkotaan. Casual Dining Restaurant di Bali dapat di wilayah Seminyak, Kuta, Jimbaran, dan Nusa Dua. Mengingat minimnya penelitian terhadap restoran sejenis di Bali, maka perlu dilakukan evaluasi mengenai kepuasan dan niat berperilaku pelanggan Casual dining restaurant berdasarkan kombinasi ketiga aspek pengalaman makan. Dengan demikian, penelitian ini bertujuan untuk menjelaskan: (1) Untuk menjelaskan pengaruh kualitas makanan terhadap kepuasan pelanggan pada Nanny's Pavillon. (2) Untuk menjelaskan pengaruh kualitas pelayanan terhadap kepuasan pelanggan pada Nanny's Pavillon. (3) Untuk menjelaskan pengaruh lingkungan fisik terhadap kepuasan pelanggan 
pada Nanny's Pavillon. (4) Untuk menjelaskan pengaruh kepuasan pelanggan terhadap niat berperilaku pada Nanny's Pavillon.

Beberapa studi seperti (Fi, 2012) mengungkapkan bahwa makanan adalah produk utama dari sebuah restoran. Kualitas makanan didefinisikan sebagai kualitas makanan yang kita konsumsi. Sebagai inti produk dari suatu restoran, makanan memainkan peran penting di dalam pengalaman ketika di restoran. Kualitas makanan telah diterima secara umum sebagai faktor utama yang mempengaruhi kepuasan konsmuen dan behavioral intetion. Clark dan Wood (2009) mengkonfirmasikan bahwa kualitas makanan merupakan faktor utama yang mempengaruhi pelanggan di dalam memilih suatu restoran. Clark dan Wood juga mengidentifikasikan kualitas makanan dan varietas makanan sepanjang dining experience sebagai faktor yang mempengaruhi pelanggan untuk menjadi loyal.

Sulek dan Hensley (2009) menemukan bahwa kualitas makanan merupakan faktor yang paling penting yang mempengaruhi kepuasan dan sebagai satu-satunya faktor yang akan memprediksikan terjadinya suatu behavioral intentions. Namkung dan Jang (2008) menguji efek dari kualitas makanan pada kepuasan konsmuen dan behavioral intention dan menemukan hubungan yang positif diantara kualitas makanan dan kepuasan konsmuen.

\section{H1: Kualitas makanan berpengaruh positif dan signifikan terhadap kepuasan pelanggan}

Beberapa peneliti membuktikan bahwa kualitas layanan merupakan hal utama yang menyebabkan kepuasaan dan niat berperilaku pelanggan setelah 
bersantap di restoran (Liu dan Jang, 2009; Namkung dan Jang 2008; serta Ryu dan Han 2010).

Studi sebelumnya menemukan bahwa terdapat pengaruh yang positif dan signifikan dari kualitas layanan terhadap kepuasaan pelanggan (Namkung dan Jang; Liu dan Jang 2009; Qin dan Pributok, 2009 Ryu dan Han, 2010; serta Canny, 2014). Indikator seperti layanan yang konsisten, kesediaan untuk membantu, keramahan, serta pengetahuan karyawan menyebabkan tingginya tingkat kepuasaan pelanggan di restoran (Namkung dan Jang 2008, Liu dan Jang 2009, serta Canny, 2014). Liu dan Jang (2009) menemukan bahwa indikator layanan yang konsisten serta karyawan yang ramah dan bersedia membantu berdampak secara signifikan terhadap kepuasaan pelanggan.

\section{H2 : Kualitas layanan berpengaruh positif dan signifikan terhadap kepuasan pelanggan}

Sejumlah penelitian di restoran menunjukkan bahwa lingkungan fisik sangat penting untuk kepuasaan dan behavioral intentions pelanggan (Namkung dan Jang, 2008; Liu dan Jang 2009a; Qin dan Prybutok, 2009; Canny, 2013; serta Canny 2014).

Lingkungan fisik ditemukan berpengaruh positif bagi kepuasaan pelanggan (Namkung dan Jang, 2008; Liu dan Jang 2009; Ryu dan Han, 2010; Heung dan Gu, 2012; serta Canny, 2014). Beberapa studi menunjukkna bahwa dimensi- dimensi lingkungan fisik seperti ambient conditions, facility aesthetics, spatial layout, serta seating comfort memiliki pengaruh yang positif dan signifikan terhadap kepuasaan (Heung dan Gu, 2012; Namkung dan Jang, 2008). 
Heung dan $\mathrm{Gu}$ (2012) yang meneliti 10 middle and upscale full- service restaurants di Hongkong menemukan bahwa aspek ambience dan facility aesthetics berdampak positif dan signifikan terhadap kepuasaan pelanggan.

\section{H3: Lingkungan fisik berpengaruh positif dan siginifikan terhadap kepuasan pelanggan}

Solomon et al. (2006:328) menyatakan bahwa kepuasaan pelanggan ditentukan oleh perasaan atau sikap secara keseluruhan yang dimiliki seseorang terhadap sebuah produk setelah menggunakan produk tersebut. . Oliver (2010:8) mendefinisikan kepuasaan pelanggan sebagai respon pemenuhan pelanggan, yang merupakan penilaian bahwa fitur atau produk atau jasa itu sendiri, menyediakan tingkat yang menyenangkan dari pemenuhan terkait konsumsi, termasuk tingkat yang di bawah atau melampaui pemenuhan.

Kepuasaan pelanggan terbukti berpengaruh positif dan signifikan terhadap niat berperilaku Han dan Jang, (2010); Ryu dan Han, (2010), serta Shanaki et al. (2012). Beberapa studi yang dilakukan pada sejumlah bidang usaha yang berbeda menunjukan bahwa pelanggan yang puas cenderung akan berkunjung kembali (Fen dan Kew, 2007), merekomendasikan kepada orang lain Shanaki et al. (2012); Wu, (2013), menceritakan hal-hal positif terkait pengalamannya (Kim et al,. 2009, Saha dan Theingi, 2009; serta Canny, 2014) serta memilih perusahaan yang sama sebagai pilihan pertama (Wu, 2013).

H4 : Kepuasan pelanggan berpengaruh positif dan signifikan terhadap niat berperilaku 
Berdasarkan hasil-hasil studi empiris diatas maka model penelitian ini dapat digambarkan sebagai berikut.

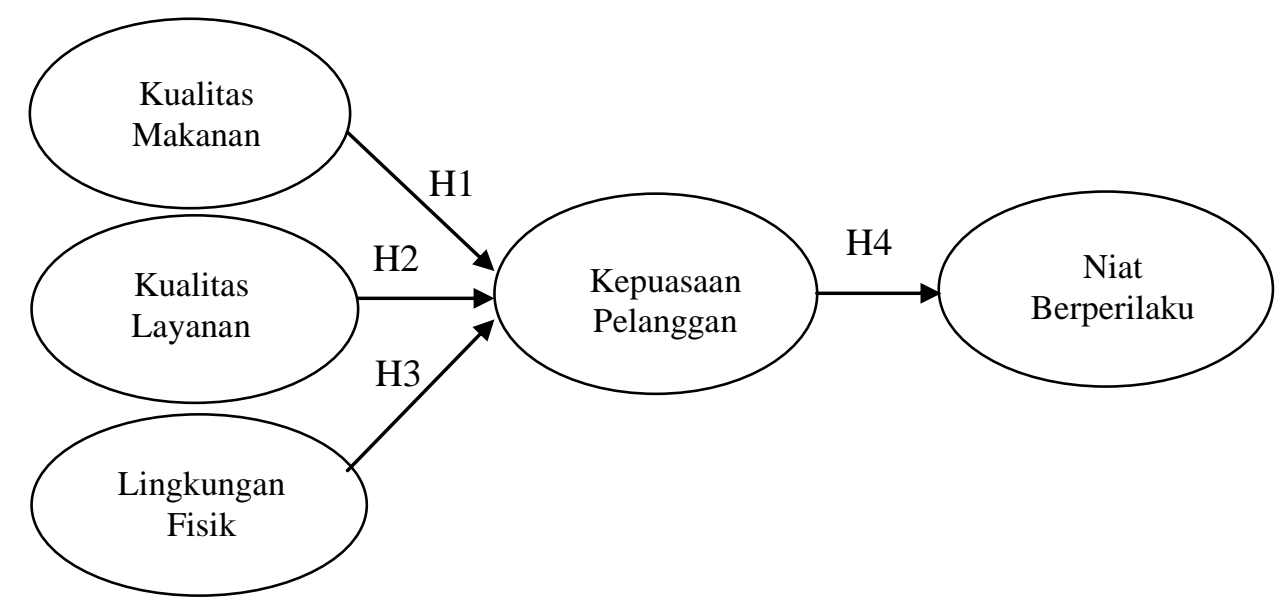

Gambar 1. Kerangka Konseptual Penelitian

\section{METODE PENELITIAN}

Ruang lingkup dalam penelitian ini adalah niat berperilaku pelanggan restoran dalam berkunjung kembali ke Nanny's Pavillon yang diperediksi oleh beberapa variabel seperti kualitas makanan, kualitas layanan serta lingkungan fisik, kepuasaan pelanggan Nanny's Pavillon, Beachwalk Bali. Ruang lingkup penelitian ini dilakukan di restoran Nanny's Pavillon, yang terletak di Kabupaten Badung- Bali.

Pada penelitian ini data kualitatif dalam penelitian ini berupa gambaran singkat mengenai Nanny's Pavillon, Bali, serta jawaban yang diperoleh dari jawaban responden yang didapat melelui kuesioner.

Data primer yang digunakan dalam penelitian ini adalah jawaban responden terhadap kuesioner yang disebarkan mengenai kualitas makanan, 
kualitas layanan, lingkungan fisik, kepuasan pelanggan dan niat berperilaku pelanggan. Data sekunder dalam penelitian ini adalah data yang diperoleh dari sumber lain yang mendukung penelitaian serta dari studi terkait berupa data yang diperoleh dari manajemen Nanny's pavillon Beachwalk, 2016.

Konstruk dalam penelitian ini disusun berdasarkan permasalahan, tujuan penelitian, landasan teori, dan hasil penelitian sebelumnya, adapun konstrukkonstruk yang digunakan dalam penelitian ini adalah konstruk eksogen terdiri atas, kualitas makanan, kualitas layanan serta lingkungan fisik. Kosnstruk endogen terdiri atas, kepuasaan pelanggan dan niat berpertilaku pelanggan.

Populasi dalam penelitian ini adalah orang- orang yang pernah berkunjung ke Nanny's dari tahun 2017. Jumlah populasi dalam penelitian ini tidak dapat diketahui dengan pasti karena tidak terdapat data base mengenai jumlah pengunjung sejak restoran beroperasi serta pelanggan bersifat mobile.

Ferdinand (2002) menyatakan bahwa ukuran sampel tergantung pada jumlah indikator dikalikan 5 sampai dengan 10. Penelitian ini menggunakan 21 indikator, sehingga jumlah sampel yang disarankan berkisar antara 105- 210 sampel. Kuesioner yang disebarkan sebanyak 150 kuesioner yang diisi dengan lengkap dan benar.

Metode pengumpulan data dalam penelitian ini menggunakan metode angket dengan menyebarkan kuesioner. Kuesioner diberikan oleh waiter pada pelanggan yang sedang menunggu proses pembayaran dan bersedia untuk mengisi kuesioner. Kuesioner terdiri atas tiga bagian. Bagian pertama pertanyaan mengenai profil responden. Bagian kedua terdiri atas daftar penyataan tentang 
Gita Ekowati Anjarsari, Ni Wayan Sri Suprapti, dan I Putu Gde Sukaatmadja. Pengaruh Kualitas...

kualitas makan, kualitas layanan, lingkungan fisik, kepuasaan, dan niat berperilaku responden. Jawaban yang diperoleh kemudian digunakan sebagai data penelitian.

Penelitian ini menggunakan statistik deskriptif dan statistik inferensial. Hipotesis penelitian diuji dengan menggunakan Structural Equation Modeling (SEM) melalui program AMOS 21.0 dan SPSS 19, untuk melihat hubungan diantara variabel-variabel penelitian.

\section{HASIL DAN PEMBAHASAN}

Profil responden berdasarkan jenis kelamin memiliki persentase responden perempuan adalah sebesar 52\% dan responden laki-laki sebesar 48\%. Data tersebut menunjukkan bahwa responden perempuan lebih mendominasi daripada responden laki-laki dalam hal berkunjung ke restoran Nanny's Pavillon. Berdasarkan dari usia, rentang usia 21-30 tahun memiliki jumlah responden yang lebih banyak, sebesar 38\%, selanjutnya diikuti oleh rentang usia 31-40 ttahun sebesar $28 \%$, usia $\leq 20$ tahun tahun sebesar $21,3 \%$, usia $41-50$ sebesar 7,4\% dan usia $>51$ tahun sebesar 5,3\%.

Berdasarkan jenis pekerjaan, responden dengan pekerjaan pegawai swasta adalah yang paling banyak yaitu sebesar 26,7\%, diikuti dengan pekerjaan wirausaha sebesar 24\%, selanjutnya pegawai negeri sebesar 12,7\% kemudian pelajar/mahasiswa sebesar 11,3\%, dan lainnya sebesar 10,6\%. Berdasarkan pendidikan rata-rata responden yang mengunjingi Nanny's Pavillon adalah mereka yang memiliki pendidikan sarjana/sederajat yang paling tinggi sebesar 
53,4\%, Selanjutnya, pendidikan pascasarjana sebesar $35,4 \%$, dan pendidikan SMA/sederajat sebesar $11,4 \%$.

Berdasarkan rata-rata penghasilan atau uang saku pengunjung Nanny's Pavillon yang paling banyak adalah penghasilan sebesar Rp. 5 juta - 10 juta sebanyak $38 \%$, selanjutnya dikuti oleh penghasilan diatas 10 juta sebanyak 25,4\%, penghasilan sebesar Rp. 1 juta - 5 juta sebanyak 23,4\%, penghasilan Rp. $<1$ juta sebesar $13,4 \%$. Selanjutnya berdasarkan teman berkunjung yang diajak ke restoran Nanny's Pavillon diantaranya adalah teman dengan jumlah jawaban terbanyak yaitu sebesar 32,6\%, selanjutnya adalah keluarga sebesar 30\%, diikuti oleh lainya sebesar $22 \%$, dan seorang diri sebesar $15,4 \%$. Dilihat dari frekuensi kunjungan ke restoran dalam 6 bulan terakhir yang dilakukan pelanggan diketahui bahwa pelanggan paling banyak pernah berkunjung ke Nanny's Pavillon adalah sebanyak lima kali sebesar 38\%, selanjutnya diikuti oleh pelanggan yang berkunjung sebanyak empat kali sebesar $26,7 \%$, pelanggan yang berkunjung sebanyak tiga kali sebesar $22 \%$ dan pelanggan yang berkunjung dua kali sebesar $13,4 \%$.

Tabel 1. Hasil Uji Goodness of Fit Model SEM

\begin{tabular}{lccc}
\hline \multicolumn{1}{c}{ Goodness of Fit } & Nilai Kritis & Nilai Model & Keterangan \\
\hline Chi-square & Diharapkan Kecil & 181,088 & Fit \\
Probability & $\geq 0,05$ & 0,505 & Fit \\
CMIN/DF & $\leq 2,00$ & 0,995 & Fit \\
GFI & $\geq 0,90$ & 0,903 & Fit \\
TLI & $\geq 0,95$ & 1,001 & Fit \\
CFI & $\geq 0,95$ & 1,000 & Fit \\
RMSEA & $\leq 0,08$ & 0,000 & Fit \\
AGFI & $\geq 0,90$ & 0,877 & Maginal \\
\hline
\end{tabular}

Sumber: Hasil Olahan Data Primer, 2017 
Gita Ekowati Anjarsari, Ni Wayan Sri Suprapti, dan I Putu Gde Sukaatmadja. Pengaruh Kualitas...

Tabel 1. menunjukkan Chi-square, Probability, CMIN/DF, GFI, TLI, AGFI, CFI, RMSEA, telah memenuhi krititeria fit. Pada nilai AGFI berada di bawah nilai kritis sebesar 0,877 yaitu kurang dari 0,90 , namun masih dalam batas toleransi yang sering disebut dengan marginal. Dalam penelitian ini nilai Chisquare yang diperoleh sebesar 171,868 yang berarti semakin kecil nilai (chisquare), maka semakin kecil perbedaan antara model dengan data. Nilai Probability pada penelitian ini adalah signifikan yaitu sebesar 0,505.

Nilai CMIN/DF dalam penelitian ini memiliki nilai 0,995 di mana nilai tersebut kurang dari 2,00. Nilai Goodness of Fit Index (GFI) dalam penelitian ini diperoleh sebesar 0,903 lebih besar dari standar yang ditetapkan sebesar 0,90 ini berarti bahwa semakin besar jumlah sampel maka semakin tinggi nilai GFI. Nilai TLI sebesar 1,001 di mana lebih dari 0,95 ini memiliki arti bahwa model dapat diterima. Nilai CFI pada model keseluruhan memiliki nilai sebesar 1,000 di mana lebih besar dari 0,95. Nilai RMSEA the Root Mean Square Error of Approximation) dalam penelitian ini memiliki nilai 0,000 di mana nilai ini lebih kecil dari standar RMSEA yaitu 0,08 yang berarti bahwa nilai tersebut menunjukkan fit model sangat baik.

Menurut Hair (1998) dalam Suliyanto (2011) sebuah indikator dinyatakan layak sebagai penyusun konstruk variabel jika memiliki Factor Loading > 0,4. Pada Tabel 2. menunjukkan hasil uji dalam SEM di mana nilai Factor Loading setiap indikator pada masing-masing konstruk menunjukkan hasil diatas 0,4 ini berarti bahwa setiap indikator dapat menjelaskan keberadaan masing-masing 
konstruknya. Kemudian pada kolom signifikansi (p) menunjukkan bahwa masingmasing indikator adalah signifikan yaitu lebih kecil dari 0,001 .

Berdasarkan output data SEM, pada Tabel 3. menunjukkan tidak terdapat nilai Critical Ratio (CR) yang sama dengan nol, sehingga hipotesis nol ditolak. Hal ini berarti hubungan kausalitas pada model penelitian berpengaruh signifikan sehingga model dapat diterima. Data juga menunjukkan semua nilai probabilitas masing-masing indikator lebih kecil dari 0,05 dan nilai estimate standardized berada di atas 0,05 . Hasil data tersebut dapat dikatakan bahwa indikator-indikator pembentukan konstruk telah menunjukkan sebagai indikator yang kuat dalam pengukuran variabel kosntruk.

Tabel 2. Hasil Uji Factor Loading

\begin{tabular}{|c|c|c|c|c|c|c|}
\hline Konstruk & Indikator & $\begin{array}{l}\text { Factor } \\
\text { Loading }\end{array}$ & S.E. & C.R. & $P$ & Label \\
\hline Kualitas & $\begin{array}{c}\text { Tampilan Makanan } \\
\left(\mathrm{X}_{1.1}\right)\end{array}$ & 0,667 & - & - & - & - \\
\hline \multirow{4}{*}{$\begin{array}{l}\text { Makanan } \\
\qquad\left(\mathrm{X}_{1}\right)\end{array}$} & Variasi Menu $\left(\mathrm{X}_{1.2}\right)$ & 0,608 & 0,239 & 4,488 & 000 & par_1 \\
\hline & Suhu Makanan $\left(\mathrm{X}_{1.3}\right)$ & 0,460 & 0,194 & 4,182 & 000 & par_2 \\
\hline & $\operatorname{Rasa}\left(\mathrm{X}_{1.4}\right)$ & 0,582 & 0,246 & 4,560 & 000 & par_3 \\
\hline & Keramahan $\left(\mathrm{X}_{2.1}\right)$ & 0,552 & - & - & - & - \\
\hline \multirow{6}{*}{$\begin{array}{l}\text { Kualitas } \\
\text { Layanan } \\
\quad\left(\mathrm{X}_{2}\right)\end{array}$} & Kesopanan $\left(\mathrm{X}_{2.2}\right)$ & 0,594 & 0,248 & 4,293 & 000 & par_1 \\
\hline & $\begin{array}{c}\text { Kesediaan } \\
\text { Membantu }\left(\mathrm{X}_{2.3}\right)\end{array}$ & 0,458 & 0,219 & 3,941 & 000 & par_2 \\
\hline & $\begin{array}{l}\text { Konsisten Melayani } \\
\qquad\left(\mathrm{X}_{2.4}\right)\end{array}$ & 0,635 & 0,247 & 4,627 & 000 & par_3 \\
\hline & Pengetahuan $\left(\mathrm{X}_{2.5}\right)$ & 0,526 & 0,221 & 4,246 & 000 & par_4 \\
\hline & Pencahayaan $\left(\mathrm{X}_{3.1}\right)$ & 0,620 & - & - & - & - \\
\hline & $\operatorname{Arsitektur}\left(\mathrm{X}_{3.2}\right)$ & 0,540 & 0,220 & 3,736 & 000 & par_1 \\
\hline \multirow[t]{3}{*}{$\begin{array}{l}\text { Lingkungan } \\
\text { Fisik }\left(\mathrm{X}_{3}\right)\end{array}$} & $\begin{array}{l}\text { Kenyamanan } \\
\text { Duduk }\left(\mathrm{X}_{3.3}\right)\end{array}$ & 0,446 & 0,178 & 3,908 & 000 & par_2 \\
\hline & $\operatorname{Musik}\left(\mathrm{X}_{3.4}\right)$ & 0,605 & 0,239 & 3,957 & 000 & par_3 \\
\hline & Pengalaman yang & & & & & \\
\hline \multirow{2}{*}{$\begin{array}{l}\text { Kepuasaan } \\
\text { Pelanggan } \\
\quad\left(\mathrm{Y}_{1}\right)\end{array}$} & Menyenangkan & 0,740 & - & - & - & - \\
\hline & $\begin{array}{c}\left(\mathrm{Y}_{1.1}\right) \\
\text { Pilihan yang Tepat } \\
\left(\mathrm{Y}_{1.2}\right)\end{array}$ & 0,633 & 0,152 & 5,917 & 000 & par_1 \\
\hline
\end{tabular}


Tabel 2. Hasil Uji Factor Loading

\begin{tabular}{|c|c|c|c|c|c|c|}
\hline Konstruk & Indikator & $\begin{array}{l}\text { Factor } \\
\text { Loading }\end{array}$ & S.E. & C.R. & $P$ & Label \\
\hline \multirow{7}{*}{$\begin{array}{l}\text { Niat } \\
\text { berperilaku } \\
\quad\left(\mathrm{Y}_{2}\right)\end{array}$} & Pengalaman yang & & & & 000 & \\
\hline & $\begin{array}{c}\text { Membuat Suasana } \\
\text { Hati lebih Baik } \\
\left(\mathrm{Y}_{1.3}\right)\end{array}$ & 0,678 & 0,145 & 6,839 & & par_2 \\
\hline & $\begin{array}{l}\text { Kepuasaan secara } \\
\text { Keseluruhan }\left(\mathrm{Y}_{1.4}\right)\end{array}$ & 0,631 & 0,153 & 6,052 & 000 & par_3 \\
\hline & $\begin{array}{c}\text { Keinginan } \\
\text { Berkunjung } \\
\text { Kembali }\left(\mathrm{Y}_{2.1}\right)\end{array}$ & 0,671 & - & - & - & - \\
\hline & $\begin{array}{c}\text { Menceritakan Hal- } \\
\text { hal Positif }\left(\mathrm{Y}_{2.2}\right)\end{array}$ & 0,560 & 0,141 & 5,414 & 000 & par_1 \\
\hline & $\begin{array}{c}\text { Merekomendasikan } \\
\text { Restoran }\left(\mathrm{Y}_{2.3}\right)\end{array}$ & 0,691 & 0,144 & 6,024 & 000 & par_2 \\
\hline & $\begin{array}{c}\text { Mempertimbangkan } \\
\text { sebagai Pilihan } \\
\text { Pertama }\left(\mathrm{Y}_{2.4}\right)\end{array}$ & 0,690 & 0,176 & 6,038 & 000 & par_3 \\
\hline
\end{tabular}

Sumber: Hasil Olahan Data Primer, 2017

Tabel 3. Regression Weight Model Struktural

\begin{tabular}{|c|c|c|c|c|c|c|c|}
\hline & & & Estimate & S.E. & C.R. & $P$ & Label \\
\hline Kepuasaan Pelanggan & $<--$ & Lingkungan Fisik & 0,390 & 0,106 & 3,689 & 000 & par_12 \\
\hline Kepuasaan Pelanggan & $<---$ & Kualitas Layanan & 0,376 & 0,122 & 3,093 & ,002 & par_13 \\
\hline Kepuasaan Pelanggan & $<---$ & Kualitas Makanan & 0,525 & 0,138 & 3,812 & 000 & par_14 \\
\hline Niat berperilaku & $<---$ & Kepuasaan Pelanggan & 1,079 & 0,137 & 7,850 & 000 & par_15 \\
\hline Tampilan Makanan & $<---$ & Kualitas Makanan & 1,000 & & & & \\
\hline Variasi Menu & $<---$ & Kualitas Makanan & 1,178 & 0,186 & 6,343 & 000 & par_1 \\
\hline Suhu Makanan & $<---$ & Kualitas Makanan & 1,270 & 0,190 & 6,669 & 000 & par_2 \\
\hline Rasa & $<---$ & Kualitas Makanan & 1,279 & 0,203 & 6,298 & 000 & par_3 \\
\hline Musik & $<---$ & Lingkungan Fisik & 1,000 & & & & \\
\hline Kenyamanan duduk & $<---$ & Lingkungan Fisik & 1,072 & 0,170 & 6,322 & 000 & par_4 \\
\hline Arsitektur & $<---$ & Lingkungan Fisik & 0,999 & 0,166 & 6,035 & 000 & par_5 \\
\hline Pencahayaan & $<---$ & Lingkungan Fisik & 1,116 & 0,179 & 6,250 & 000 & par_6 \\
\hline $\begin{array}{l}\text { Kepuasan secara } \\
\text { Keseluruhan }\end{array}$ & $<---$ & Kepuasaan Pelanggan & 1,000 & & & & \\
\hline $\begin{array}{l}\text { Pengalaman yang } \\
\text { membuat suasan hati } \\
\text { lebih baik }\end{array}$ & $<---$ & Kepuasaan Pelanggan & 1,055 & 0,137 & 7,714 & 000 & par_7 \\
\hline Pilihan yang tepat & $<---$ & Kepuasaan Pelanggan & 0,979 & 0,132 & 7,439 & 000 & par_8 \\
\hline
\end{tabular}


ISSN : 2337-3067

E-Jurnal Ekonomi dan Bisnis Universitas Udayana 7.5 (2018): 1347-1374

\begin{tabular}{|c|c|c|c|c|c|c|c|}
\hline & & & Estimate & S.E. & C.R. & $\mathrm{P}$ & Label \\
\hline $\begin{array}{l}\text { Pengalaman yang } \\
\text { menyenangkan }\end{array}$ & $<---$ & Kepuasaan Pelanggan & 1,017 & 0,127 & 7,986 & 000 & par_9 \\
\hline $\begin{array}{l}\text { Keinginan berkunjung } \\
\text { kembali }\end{array}$ & $<---$ & Niat berperilaku & 1,000 & & & & \\
\hline $\begin{array}{l}\text { Menceritakan hal-hal } \\
\text { positif }\end{array}$ & $<---$ & Niat berperilaku & 0,854 & 0,109 & 7,849 & 000 & par_10 \\
\hline $\begin{array}{l}\text { Merekomendasikan } \\
\text { Restoran }\end{array}$ & $<---$ & Niat berperilaku & 0,735 & 0,100 & 7,361 & 000 & par_11 \\
\hline $\begin{array}{l}\text { Mempertimbangkan } \\
\text { sebagai pilihan pertama }\end{array}$ & $<---$ & Niat berperilaku & 0,898 & 0,122 & 7,345 & 000 & par_16 \\
\hline Pengetahuan & $<---$ & Kualitas Layanan & 1,000 & & & & \\
\hline $\begin{array}{l}\text { Konsisten dalam } \\
\text { melayani }\end{array}$ & $<---$ & Kualitas Layanan & 0,984 & 0,169 & 5,805 & 000 & par_20 \\
\hline $\begin{array}{l}\text { Kesediaan untuk } \\
\text { Membantu }\end{array}$ & $<---$ & Kualitas Layanan & 1,204 & 0,188 & 6,388 & 000 & par_21 \\
\hline Kesopanan & $<---$ & Kualitas Layanan & 1,055 & 0,173 & 6,084 & 000 & par_22 \\
\hline Keramahan & $<---$ & Kualitas Layanan & 1,036 & 0,174 & 5,963 & 000 & par_23 \\
\hline
\end{tabular}

Sumber: Hasil Olahan Data Primer, 2017

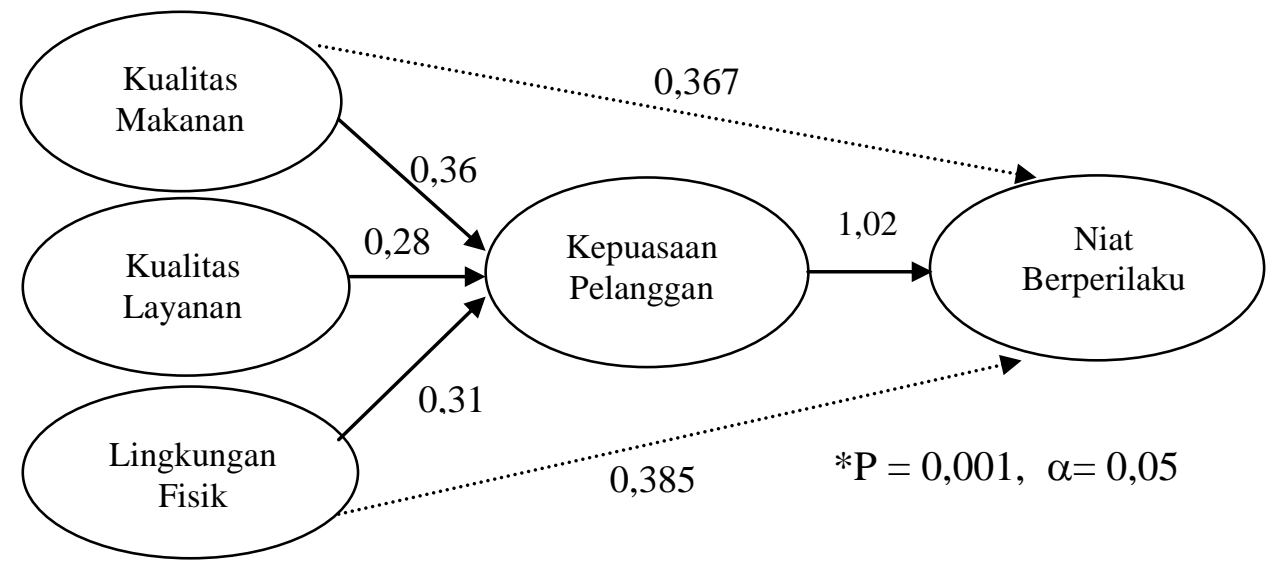

Sumber: Olahan Data Primer, 2017

\section{Gambar 2. Measurement Model}

\section{Pengaruh Langsung dan Pengaruh Tidak Langsung}

Hasil olah data menunjukkan, pengaruh langsung dari kualitas makanan terhadap kepuasaan pelanggan adalah sebesar 0,36. Pengaruh langsung konstruk kualitas layanan terhadap kepuasaan pelanggan adalah sebesar 0,28, dan Pengaruh 
Gita Ekowati Anjarsari, Ni Wayan Sri Suprapti, dan I Putu Gde Sukaatmadja. Pengaruh Kualitas...

langsung lingkungan fisik terhadap kepuasaan pelanggan adalah sebesar 0,31. Nilai tersebut menunjukkan bahwa konstruk lingkungan fisik memiliki pengaruh yang lebih rendah daripada kualitas makanan dan kualitas layanan. Pengaruh langsung kepuasaan pelanggan terhadap niat berperilaku adalah sebesar 1,02.

Hasil olah data menunjukkan bahwa pengaruh tidak langsung dari kualitas makanan terhadap niat berperilaku memiliki nilai sebesar 0,367 . Pengaruh tidak langsung kualitas layanan terhadap persepsi niat berperilaku adalah sebesar 0,385 , dan pengaruh tidak langsung lingkungan fisik terhadap persepsi niat berperilaku adalah sebesar 0,316 ini menunjukkan bahwa pengaruh tidak langsung lingkungan fisik lebih rendah daripada kualitas makanan dan kualitas layanan.

\section{Pengaruh kualitas makanan terhadap kepuasan pelanggan}

Berdasarkan hasil uji hipotesis menemukan bahwa hipotesis satu yaitu pengaruh kualitas makanan berpengaruh positif dan signifikan terhadap kepuasan pelanggan. Hasil ini didukung dengan nilai probability sebesar $0,002(<0,05)$ dan nilai koefisien sebesar 0,36 . Ini berarti bahwa semakin baik kualitas makanan yang dirasakan pelanggan, maka semakin tinggi kepuasan yang dirasakan pelanggan terhadap restoran Nanny's Pavillon. Kualitas makanan merupakan faktor yang paling penting yang mempengaruhi kepuasan dan sebagai satusatunya faktor yang akan memprediksikan terjadinya suatu behavioral intention.

Penelitian yang dilakukan Canny (2013) menggunakan 213 responden dari dua casual dining restaurants ternama di Selatan menemukan bahwa kualitas makanan berpengaruh terhadap kepuasan pelanggan, terutama aspek tampilan makanan. Penelitian Sulek dan Hensley (2009) menyatakan bahwa makanan 
merupakan bagian paling penting dari keseluruhan pengalaman makan di restoran di mana pada penelitian mereka juga menemukan bahwa kualitas makanan berpengaruh positif dan signifikan terhadap kepuasan pelanggan. Penelitian lainnya yaitu Namkung dan Jang (2008), Liu dan Jang (2009a), Qin dan Prybutok (2009) juga menemukan bahwa kualitas makanan mempengaruhi kepuasan pelanggan yang selanjutnya akan mempengaruhi niat berperilaku pelanggan

\section{Pengaruh kualitas layanan terhadap kepuasan pelanggan}

Berdasarkan hasil uji hipotesis menemukan bahwa hipotesis dua yaitu pengaruh kualitas layanan berpengaruh positif dan signifikan terhadap kepuasan pelanggan. Hasil ini didukung dengan nilai probability sebesar $0,000(<0,05)$ dan nilai koefisien sebesar 0,28 . Ini berarti bahwa semakin baik kualitas pelayanan yang dirasakan pelanggan maka, semakin tinggi kepuasan yang dirasakan pelanggan terhadap restoran Nanny's Pavillon.

Hasil penelitian ini mendukung penelitian sebelumnya yaitu Ryu dan Han (2010) melakukan penelitian terhadap 360 pelanggan pada tiga restoran cepat saji menemukan bahwa kualitas layanan berpengaruh positif dan signifikan terhadap kepuasan pelanggan. Liu dan Jang (2009) juga menemukan di menemukan kualitas layanan yang konsisten serta karyawan yang ramah dan bersedia membantu berdampak secara positif dan signifikan terhadap kepuasaan pelanggan. Qin dan Pributok (2009) pada penelitiannya juga menemukan pengaruh kualitas makanan yang positif dan signifikan terhadap kepuasan pelanggan pada restoran cepat saji. Hasil penelititian lainnya yaitu Namkung dan Jang (2008), Ryu dan Han (2010) serta Canny (2014). 


\section{Pengaruh lingkungan fisik terhadap kepuasan pelanggan}

Berdasarkan hasil uji hipotesis menemukan bahwa hipotesis tiga yaitu pengaruh lingkungan fisik berpengaruh positif dan signifikan terhadap kepuasan pelanggan. Hasil ini didukung dengan nilai probability sebesar $0,000(<0,05)$ dan nilai koefisien sebesar 0,31 . Ini berarti bahwa semakin baik lingkungan fisik yang dirasakan pelanggan maka, semakin tinggi kepuasan yang dirasakan pelanggan terhadap restoran Nanny's Pavillon.

Pada penelitin Heung dan Gu (2012), yang meneliti 10 middle and upscale full- service restaurants di hongkong menemukan bahwa kualitas lingkungan fisik restoran memiliki pengaruh yang positif dan signifikan terhadap kepuasaan pelanggan. Canny (2014) juga menemukan hasil yang sama kualitas lingkungan memiliki pengaruh positif dan signifikan terhadap kepuasan pelanggan di mana penelitiannya dilakukan pada restoran casual dinning di jakarta. Beberapa hasil penelitian sebelumya juga menemukan bahwa lingkungan fisik berpengaruh positif dan signifikan terhadap kepuasaan pelanggan diantaranya adalah Namkung dan Jang (2008), Liu dan Jang (2009).

\section{Pengaruh kepuasan pelanggan terhadap niat berperilaku}

Berdasarkan hasil uji hipotesis menemukan bahwa hipotesis empat yaitu pengaruh kepuasan pelanggan berpengaruh positif dan signifikan terhadap niat berperilaku pelanggan. Hasil ini didukung dengan nilai probability sebesar 0,000 $(<0,05)$ dan nilai koefisien sebesar 1,02. Ini berarti bahwa semakin baik kepuasan yang dirasakan pelanggan maka, semakin tinggi niat berperilaku pelanggan untuk 
merekomendasikan dan menceritakan hal-hal positif serta berkunjung kembali ke restoran Nanny's Pavillon.

Hasil penelitian yang dilakukan $\mathrm{Wu}$ (2013) yang dilakukan terhadap 686 pelanggan yang pernah mengunjung restoran cepat saji ( McDonald's, Burger king, KFC, MOS Burger, dan Wendy's) di Taipe menunjukkan hasil bahwa kepuasan berpengaruh positif terhadap niat berperilaku pelanggan. Hasil yang sama yaitu kepuasan pelanggan berpengaruh positif dan signifikan terhadap niat berperilaku juga ditemukan pada penelitian sebelumnya yaitu Ryu dan Han, (2010) serta Shanaki et al. (2012).

\section{Implikasi Penelitian}

Implikasi teoritis pada penelitian ini untuk memperkaya ilmu pemasaran khususnya mengenai perilaku pelanggan dan juga memperkuat hasil penelitian sebelumnya yang menunjukkan bahwa kualitas makanan, kualitas layanan, dan lingkungan fisik mempengaruhi kepuasan pelanggan, dan selanjutnya akan mempengaruhi niat berperilaku pelanggan.

Adapun implikasi praktis yang dapat di berikan dalam penelitian ini yang pertama penelitian ini menemukan bahwa kualitas makanan memiliki pengaruh yang paling kuat terhadap kepuasan yang dirasakan pelanggan, selanjutnya diikuti oleh lingkungan fisik pada restoran Nanny's Pavillon. Hal tersebut menjelaskan bahwa penting bagi manajer restoran Nanny's Pavillon tetap menjaga dan meningkatkan kualitas makanan yang dimiliki terutama pada hidangan yang disajikan agar selalu sesuai dengan suhu yang seharusnya, karena hal tersebut merupakan hal utama yang menjadi pertimbangan pelanggan dalam penilaian 
Gita Ekowati Anjarsari, Ni Wayan Sri Suprapti, dan I Putu Gde Sukaatmadja. Pengaruh Kualitas...

terhadap kualitas makanan. Lingkungan fisik yang menarik dan dapat memberikan atsmofer yang baik bagi pelanggan juga dapat memberilan kepuasan pada pelanggan, penting bagi manajer Nanny's Pavillon untuk senantiasa dapat membuat arsitektur restoran menjadi menarik dari waktu ke waktu dan musik yang diputar dapat menghibur pelanggan sehingga suasana yang diterima pelanggan dapat memberikan kenyamanan.

Kedua, hasil penelitian menunjukkan bahwa kepuasan pelanggan memiliki pengaruh yang kuat terhadap niat berperilaku pelanggan. Kepuasan pelanggan terhadap Nanny's Pavillon dipengaruhi oleh kualitas pelanggan, kualitas layanan, dan lingkungan fisik. Kepuasan pelanggan pada Nanny's Pavillon tentunya akan berdapak baik terhadap niat dan perilaku pelanggan, karena saat pelanggan merasa puas maka anan mempengaruhi perilaku pelanggan seperti berniat untuk merekomendasikan dan menceritakan hal-hal positif mengenai Nanny's Pavillon kepada teman-teman atau orang-orang terdekat mereka. Tentunya dengan kepuasan yang dirasakan pelanggan juga akan memunculkan niat pelanggan untuk kembali datang ke Nanny's Pavillon restoran.

Adapun implikasi praktis yang dapat di berikan dalam penelitian ini yang pertama penelitian ini menemukan bahwa kualitas makanan memiliki pengaruh yang paling kuat terhadap kepuasan yang dirasakan pelanggan, selanjutnya diikuti oleh lingkungan fisik pada restoran Nanny's Pavillon. Hal tersebut menjelaskan bahwa penting bagi manajer restoran Nanny's Pavillon tetap menjaga dan meningkatkan kualitas makanan yang dimiliki terutama pada hidangan yang disajikan agar selalu sesuai dengan suhu yang seharusnya, karena hal tersebut 
merupakan hal utama yang menjadi pertimbangan pelanggan dalam penilaian terhadap kualitas makanan. Lingkungan fisik yang menarik dan dapat memberikan atsmofer yang baik bagi pelanggan juga dapat memberilan kepuasan pada pelanggan, penting bagi manajer Nanny's Pavillon untuk senantiasa dapat membuat arsitektur restoran menjadi menarik dari waktu ke waktu dan musik yang diputar dapat menghibur pelanggan sehingga suasana yang diterima pelanggan dapat memberikan kenyamanan.

Kedua, hasil penelitian menunjukkan bahwa kepuasan pelanggan memiliki pengaruh yang kuat terhadap niat berperilaku pelanggan. Kepuasan pelanggan terhadap Nanny's Pavillon dipengaruhi oleh kualitas pelanggan, kualitas layanan, dan lingkungan fisik. Kepuasan pelanggan pada Nanny's Pavillon tentunya akan berdapak baik terhadap niat dan perilaku pelanggan, karena saat pelanggan merasa puas maka anan mempengaruhi perilaku pelanggan seperti berniat untuk merekomendasikan dan menceritakan hal-hal positif mengenai Nanny's Pavillon kepada teman-teman atau orang-orang terdekat mereka. Tentunya dengan kepuasan yang dirasakan pelanggan juga akan memunculkan niat pelanggan untuk kembali datang ke Nanny's Pavillon restoran.

\section{SIMPULAN DAN SARAN}

Berdasarkan hasil pembahasan penelitian yang telah dilakukan, maka dapat disimpulkan bahwa: (1) Kualitas makanan berpengaruh positif dan signifikan terhadap kepuasan pelanggan. Artinya, semakin baik kualitas makanan yang disajikan kepada pelanggan, maka semakin tinggi kepuasan yang dirasakan pelanggan.(2) Kualitas layanan berpengaruh positif dan signifikan terhadap 
Gita Ekowati Anjarsari, Ni Wayan Sri Suprapti, dan I Putu Gde Sukaatmadja. Pengaruh Kualitas...

kepuasan pelanggan. Artinya, semakin baik kualitas layanan yang diberikan pada pelanggan maka semakin tinggi kepuasan yang dirasakan pelanggan.(3) Lingkungan fisik berpengaruh positif dan signifikan terhadap kepuasan pelanggan. Artinya, semakin baik lingkungan fisik yang ditampilkan pada restoran, maka semakin tinggi kepuasan yang dirasakan pelanggan.(4) Kepuasan pelanggan berpengaruh positif dan signifikan terhadap niat berperilaku pelanggan. Artinya, semakin baik kepuasan yang dirasakan pelanggan, maka semakin tinggi niat berperilaku pelanggan.

Adapun saran yang dapat diberikan berdasarkan hasil penelitian yaitu, (1) Nanny's Pavillon agar tetap dapat mempertahankan kualitas makanan yang dimiliki karena merupakan salah satu variabel yang paling memperngaruhi kepuasaan pelanggan. Mempertahankan cita rasa makanan, menjaga suhu makanan sesuai dengan yang seharusnya, dan memberikan tampilan makanan yang lebih menarik..(2) Dilihat dari profil responden berdasarkan usia, rata-rata usia yang berkunjung ke Nanny's Pavillon adalah responden yang berusia 21-42 tahun dimana kebanyakan dari mereka telah berkeluarga dan memniliki anak. sehingga pihak manajemen diharapkan untuk membuat inovasi terhadap menu makanan seperti menu makanan yang kids friendly. (3) Kualitas makanan, kualitas layanan, dan lingkungan fisik memberikan petunjuk pada Nanny's Pavillon untuk terus melakukan evaluasi dan meningkatkan kualitas restoran yang dimiliki agar sesuai dengan kebutuhan dan harapan pelanggan. (4) penelitian selanjutnya agar lebih memperluas cakupan wilayah penelitian tidak hanya Nanny's Pavillon yang ada di Bali sehingga hasil penelitian ini mencakup wilayah yang lebih luas. 
Penelitian ini juga dapat direplikasi terhadap perusahaan yang bergerak dibidang yang sama seperti pada Fine dining restaurant, dan quick service restaurant dan dapat menggunakan produk makanan lainnya sepertian organic food, Indonesian food, dan asian food. Pada penelitian selanjutnya dapat menambahkan variabel lain seperti price fairness dan food heatlhiness.

\section{REFERENSI}

Andaleeb, S., dan C. Carolyn. 2006. Costumer satisfaction in the restaurant industry: an examination of the transaction-specific model. Journal of Service Marketing. Vol. 20 No. 1, pp. 3-1.

Canny, I. U. 2013. The Role of Food Quality, Service Quality, and Physical Environment on Customer Satisfaction and Future Behavioral intentions in Casual Dining Restaurant, Konferensi Nasional Riset Manajemen. Vol. 3 No. 1,pp. 42-61.

Canny, I. U. 2014. Measuring the mediating role of dining experience attributes on customer satisfaction and its impact on behavioral intentions of casual dining restaurant in Jakarta. International Journal of Innovation, Management and Technology. Vol. 5, No. 1. pp. 25-29.

Fen, Y.S and Kew, L. K. 2007. Service duality and cumtomer satisfaction: anteccedents of customer's re-patronagen intentions. Sunway Academi journal. Vol.4, No.5, pp. 59-73

Ferdinand, A. 2002. Stuctural Equation Modeling dalam Penelitian Manajemen. Semarang: Badan Penerbit Universitas Diponegoro.

Ghozali, I. 2008. Structural Equation Modeling : Metode Alternatif Dengan Partial Least Square. Semarang : Badan Penerbit Universitas Diponegoro.

Ha, J., dan S. Jang. 2012. The effects of dining atmospherics on behavioral intentions through quality perception. Journal of Services Marketing. Vol. 26 No. 3, pp. 204- 215.

Ha, J., dan S. Jang. 2010. Perceived values, satisfaction, and behavioral intentions: The role of familiarity in Korean restaurants. International Journal of Hospitality Management. Vol. 29 No. 1, pp 2-13. 
Han, H., dan R. Kisang. 2009. The Roles of the Physical Environment, Price Perception, and Customer Satisfaction in Determining Customer Loyalty in the Restaurant Industry. Journal of Hospitality \& Tourism Research. Vol. 33, No. 4, pp. 487-510.

Hair, J.F., Anderson, R.E., Tatham, R.L. dan Black W.C.2010. Multivariate Data Analysis $4^{\text {th }}$ Edition. New Jersey: Prentice-Hall.

Heung, V.C.S. dan Gu, T. 2012. Influence of restaurant atmospherics on patron satisfaction and behavioral intentions, International Journal of Hospitality Management. Vol. 31 No.4, pp. 1167-1177.

Hersanti, N., dan R. Kusuma. 2012. Pengaruh Atmosfer Terhadap Kepuasaan dan Niatan Perilaku Pelanggan di Toko "Oen", Kota Malang. Jurnal Aplikasi Manajemen. Vol. 10, No. 4, pp. 1167-1177.

Jang, S. dan Namkung, Y. 2009. Perceived quality, emotions, and behavioral intentions: application of an extended Mehrabian-Russell model to restaurants. Journal of Business Research. Vol. 62 No.4, pp 451- 460.

Jang, SooCheong (Shawn), Yinghua Liu dan Young Namkung 2011. Effect of Authentic atmospherics in etnic restaurant investigating Chinese restaurants. International Journal of Contemporary Hospitality Management. Vol.32,pp. 121-131.

Kotler, P. 2003. Manajemen Pemasaran (11th ed.). Jakarta: Indeks Kelompok Gramedia.

Latan, H. 2012. Structural Equation Modeling : Konsep dan Aplikasi Menggunakan Program LISEL. 8.80. Bandung : Alfabeta

Lee, H.S. 2010. Factors Influencing Customer Loyalty of Mobile Service: Empirical Evidence from Koreans. Journal of International Banking and Commerce. Vol. 15, No. 2, pp. 1-14.

Leoma, C., dan Subagio, H. 2014. The effects of dining experience to behavioral intentions with customer satisfaction as an intervening variable. Journal of Marketing Management. Vol.2 No.1.

Liu, Yinghua dan SooCheong (Shawn) Jang. 2009a. Perceptions of Chinese restaurants in the U.S,: What effects customer satisfaction and behavioral intentions? International Journal of Hospitality Management. Vol. 28 No. 3, pp. 338-348. 
Liu, Yinghua dan SooCheong (Shawn) Jang. 2009b. The effects of dining atmospherics: An extended Mehrabian-Russell model. International Journal of Hospitality Management. Vol. 28 No.4,pp. 494-503.

Namkung, young dan SooCheong (shawn) Jang. 2007. Does food quality really matter in restaurant? Its impact on customer satisfaction and behavioral intentions. Journal of Hospitality \& Tourism Research. Vol. 31, No. , pp387-410.

Namkung, young dan SooCheong (Shawn) Jang 2008. Are highly satisfied restaurant costumers really different? A quality perception perspective. International Journal of Contemporary Hospitality Management. Vol. 20 No. 2, pp. 142-155.

Namkung, young dan SooCheong (Shawn) Jang. 2009. Perceived quality emotions, and behavioral intentions: Application of extended MehrabianRussell model to restaurants. Journal of Business Research. Vol. 62, No. 4, pp 451-460.

Oliver, Richard L. 2010. Satisfaction: A Behavioral Perspective on the Consumer. New York: M. E. Sharpe.

Parasuraman, A., Valarie A. Zeithmal and leonard L. Berry. 1988. SERVQUAL: A Multiple-Item Scale for Measuring Consumer Perceptions of service Quality. Journal of Reatailing. Vol. 64, No. 1,pp. 12-40.

Qin, Hong dan Victor R. Prybutok. 2009. Service quality, Customer satisfaction, and behavioral intentions in fast- food restaurants. International Journal of Quality and Service Sciences. Vol. 1, No 1, 2009. Pp. 78-95.

Ryu, K., Lee, H., dan Kim, W. G. 2011. The influence of the quality of the physical environment, food, and service on restaurant image, customer perceived value, customer satisfaction, and behavioral intentions. International Journal of Contemporary Management. Vol. 24 No. 2, pp. 200-223.

Ryu, K., dan Han, H. 2010. Influence of physical environment on disconfirmation, customer satisfaction, and customer loyalty for first-time and repeat customers in upscale restaurants. International Journal of Contemporary Hospitality Management Vol.22, No 3.

Ryu, K., Han., dan Jang, S. 2009. Relationship among hedonic and utilitarian values, satisfaction and behavioral intentions in the fast-casual restaurant industry. International Journal of Contemporary Hospitality Management Vol. 22 No.3, pp. 416-432. 
Gita Ekowati Anjarsari, Ni Wayan Sri Suprapti, dan I Putu Gde Sukaatmadja. Pengaruh Kualitas...

Ryu, Kisang, Hye- Rin Lee dan Woo Gon Kim. 2012. The influence of the quality of the physical environment, food, and service on restaurant image, costumer perceived value, costumer satisfaction, and behavioral intentions. International Journal of Contemporary Hospitality Management. Vol. 24 No. 2,pp. 200-223.

Saha, Gour C. dan Theingi. 2009, Service quality, satisfaction, and behavioral intentions: A study of low- cost airline carriers in Thailand. Managing Service Quality. Vol. 19 No. 3, pp. 350-372.

Sekaran, U. 2006. Metodologi Penelitian Untuk Bisnis, Edisi 4. Penerbit Salemba Empat.

Shanaki, M., Ranjbar, V., dan Shakhsian, F. 2012. Investigation on relationship between service quality and customer satisfaction. Indian Journal of Science and Technology. Vol. 5 No. 12, pp. 3809-3818.

Solomon, Michael, Gary Basmossy, Soren Askegaard dan Margaret K. Hogg. 2006. Cosumer Behavior: A Europe Perspective, Third Edition. London: Prentice Hall.

Suliyanto. 2011. Ekonomitrika Terapan-Teori dan Aplikasi dengan SPSS. Edisi I. Yogyakarta: CV. Andi Offset.

Sulek, Joanne M. dan Rhonda L. Hensley. 2004. the Relative Important of Food, Atmosphere, and Fairness of wait: The case of a Full- service Restaurant. Cornell Hotel and restaurant Administration Quarterly. Vol. 45 No. 3, pp 235-247.

Wu, Hung-Che. 2013. An Empirical Study of the Effects of Service Quality, Perceived Value, Corporate Image, and Cutomer Satisfaction on Behavioral intentions in the Taiwan Quick Service Restaurant Industry. Journal of Quality Assurance in Hospitality \& Tourism. Vol. 14 No.4,pp.364-390.

www.bali.bps.go.id.

www.Nanny's pavillon.com 